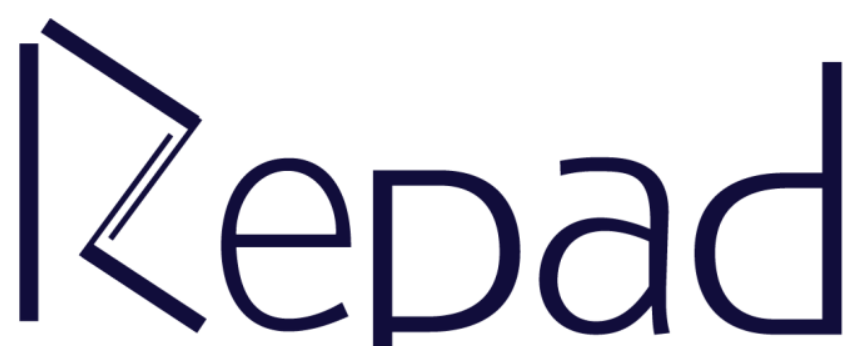

v. 4, n. 2, Maio-Agosto/2020

Revista Estudos e

Pesquisas em Administração

(C) (i) This work is licensed under a Creative Commons Attribution 4.0 International License 


\title{
O COACHING COMO FERRAMENTA PARA DESENVOLVER COMPETÊNCIAS: Um estudo de caso na Secretaria de Planejamento do Estado de Alagoas - SEPLAG
}

Fernandes Palmeira dos Santos http://orcid.org/0000-0001-8411-0781

Universidade Estadual de Alagoas

Maceió-Alagoas, Brasil

Edilene Gomes Queiroz Siqueira http//orcid.org/0000-0002-0796-262X

Universidade Estadual de Alagoas

Maceió-Alagoas, Brasil

Katia Jeane Alves Mota Ramos http://orcid.org/0000-0003-3683-4237

Universidade Estadual de Alagoas

Maceió-Alagoas, Brasil

Orlando Ramos Nascimento Jr. http://orcid.org/0000-0002-2260-8864

Universidade Estadual de Alagoas

Maceió-Alagoas, Brasil

\begin{abstract}
RESUMO
Este artigo analisou a possibilidade do uso do coaching como auxiliar no processo da gestão por competência. O presente estudo visou responder a seguinte indagação, quais as dificuldades no desenvolvimento e aprimoramento da gestão por competência? E teve como objetivo analisar as possíveis soluções para as dificuldades no desenvolvimento da gestão por competências. Abordando os diversos conceitos de competência, as formas de implantação desse modelo de gestão, as dificuldades encontradas na implantação desse modelo, e as formas de soluciona-las, tendo em vista o coaching como a principal ferramenta de solução. Foi adotada como metodologia deste estudo a pesquisa bibliográfica, o estudo de caso, e na coleta de dados incluiu livros, periódicos, artigos científicos entre outras fontes. Foi utilizado um questionário contendo 10 itens para avaliar a percepção de pessoas que vivenciam o processo da gestão por competência. A partir da coleta de dados foi possível obter conclusões parciais sobre o uso do coaching como uma ferramenta essencial para a implantação da gestão por competências, auxiliando no desenvolvimento e aprimoramento das competências individuais, e por sua vez, organizacionais.
\end{abstract}

Palavras-chave: Competência. Desenvolvimento. Organização. Coaching. 


\title{
COACHING AS A TOOL TO DEVELOP SKILlS: A case study at the Planning Secretariat of the State of Alagoas - SEPLAG
}

\begin{abstract}
This article analyzes the possibility of using coaching as an aid in the process of competency management. The present study aims to answer the following question, what are the difficulties in the development and improvement of competence management? And it aims to analyze the possible solutions to the difficulties in the development of competence management. Addressing the various concepts of competence, the ways of implementation of this management model, the difficulties encountered in the implementation of this model, and the ways to solve them, in view of coaching as the main solution tool. Bibliographic research and case study were adopted as the methodology of this study, including books, journals, scientific articles and other sources. A questionnaire containing 10 items was used to assess the perception of people who experience the competency management process. From the data collection it was possible to obtain partial conclusions about the use of coaching as an essential tool for the implementation of competency management, assisting in the development and improvement of individual and organizational competencies.
\end{abstract}

Keywords: Competence. Development. Organization. Coaching.

Submetido: $21 / 04 / 2020$

Aceito: 10/05/2020

Publicado: 31/05/2020

\section{CONSIDERAÇÕES INICIAIS}

A gestão por competência tornou-se um tema de grande relevância frente ao cenário atual, onde o mundo globalizado, com diversos avanços na área da tecnologia e da informática, força a modificação do modelo tradicional de gestão de pessoas, para a gestão por competências, devido ao antigo modelo ser considerado inadequado para esses avanços. (DUTRA et al, 2008). Tornando-se assim, um modo de gestão focado no capital humano, nesta perspectiva, vale ressaltar que os recursos humanos representam a força motriz para qualquer empresa/ organização, visto que representa um recurso vivo e decisivo no processo de manipulação dos demais, o que se revela como o mais diferenciado e dinâmico dos recursos.

Hoje pode observa-se a importância da coordenação de esforços de diferentes indivíduos, otimizando suas habilidades e preservando seu capital intelectual, "o prolongamento direto da competência que o indivíduo mobiliza em face de uma situação profissional cada vez mais mutável e complexa" (FLEURY; FLEURY, 2004, p. 3) a fim de aumentar e desenvolver novas e mais eficientes competências, com vistas a intensificar e possibilitar o alcance dos objetivos organizacionais.

Dessa forma, se faz necessário questionar quais as dificuldades no desenvolvimento e aprimoramento da gestão por competência? Pois por meio deste questionamento é possível identificar possíveis formas de sanar essas dificuldades. Como por exemplo, o coaching ferramenta muito importante no desenvolvimento de competências individuais, que por sua vez influenciam no desenvolvimento de 
competências organizacionais e foi a partir das transformações de natureza produtiva e social que atingiram as economias industrializadas, que a questão da gestão por competência foi ganhando espaço no contexto organizacional.

Nessa perspectiva, o conceito de competência foi abordado como um conjunto de conhecimentos, habilidades e atitudes que justificam um alto desempenho, na medida em que há também um pressuposto de que os melhores desempenhos estão fundamentados na inteligência e na personalidade das pessoas. Logo sob esta linha de análise, considera-se a competência, portanto, como um estoque de recursos que o indivíduo detém.

Os recursos humanos têm como base as competências dos indivíduos que compõem as equipes de desenvolvimento. A gestão de pessoas empreende ações voltadas à capacitação e integração de pessoas, valorização de equipes para a descentralização dos processos decisórios exigidos pela redução dos níveis hierárquicos. As ações, entretanto, não possuem o caráter de qualificação, mas um sentido que leva ao desenvolvimento de novas competências, integrando as potencialidades de cada sujeito ao capital organizacional. Somente com equipes coesas e desenvolvidas será possível gerir a competitividade, as incertezas e as formas de adaptabilidade requeridas para o mundo atual (BARRETO, 2005).

Para Lopez (2016), o coaching representa a técnica de auxílio para ajudar aos colaboradores, conduzindo-os na direção que se deseja alcançar. Logo, seu objetivo leva à mudança de pensamento, ajudando a realizar seus objetivos e superar os obstáculos.

\section{REFERENCIAL TEÓRICO}

\subsection{GESTÃO POR COMPETÊNCIA}

Segundo Oliveira et al. (2009), a globalização e os avanços tecnológicos vêm proporcionando ás organizações um ambiente competitivo. Onde focar apenas no produto final e no lucro da empresa não é mais suficiente para que as organizações se adaptem aos novos desafios. Em decorrência destas transformações o modelo de gestão organizacional passou por mudanças. Ter funcionários capazes de cumprir somente as tarefas que foram contratadas para fazer, não supria mais essa necessidade.

O principal recurso das organizações deixou de ser a matéria prima, e o capital financeiro, para ser o capital intelectual. As competências das organizações se modificam a partir das competências que cada funcionário pode oferecer a empresa. Dessa forma, a gestão passou de um controle dos funcionários, para uma forma de garantir o desenvolvimento das competências dos colaboradores, que por sua vez desenvolve as competências organizacionais.

Fleury e Fleury (2004) definem competência como uma palavra do senso comum, utilizada identificar uma pessoa apta para efetuar algo. O contrário de competência não indica somente a não existência de capacidade, mas acompanha certo nível de discriminação e julgamento. Indicando até uma possível marginalização no ambiente de trabalho, ou até mesmo em sua identificação pessoal.

Prahalad e Hamel (1990) definem o conceito a partir do ponto de vista organizacional, para os autores, competência é um conjunto de conhecimentos, habilidades, tecnologias, sistemas físicos, gerenciais e valores que proporcionam um 
aspecto único de cada organização. Segundo os mesmos, as competências essenciais são aquelas que os distinguem das demais organizações, e proporcionam uma vantagem competitiva, onde pode ser facilmente identificado pelos clientes e raramente podem ser copiadas pela concorrência.

Por meio disto, é possível afirmar que a organização obtém várias competências organizacionais, que por sua vez, estão localizadas em diferentes áreas, mas somente algumas podem ser consideradas competências essenciais, apenas aquelas que lhes tornam únicas, diferenciando-as de outras empresas e agregando vantagem competitiva frente a outras organizações (MORCERF; SEABRA; VILAS BOAS, 2006).

Para ser considerada uma competência essencial, não é necessário ser uma tecnologia. É possível estar associado ao controle de algum ramo da organização, ter conhecimento sobre as operações, ou os mercados específicos para o desenvolvimento da empresa. Assim como, é preciso para ser considerada competência essencial, o conhecimento precisa ter relação com um estruturado processo de aprendizagem, com inovação, com identificação e absorção de recursos humanos (MORCERF; SEABRA; VILAS BOAS, 2006).

De acordo com Fleury e Fleury (2004), há seis tipos de saberes, definidos como competência: saber agir equivale, a saber, tomar uma atitude, dizendo o que e porque faz, assim como tomar uma decisão, julgar e ter autonomia para escolher entre determinada atividade; saber mobilizar significa direcionar um determinado recurso, de pessoa ou financeiro; saber comunicar, assegurando a compreensão e retransmissão da informação; saber aprender, utilizar meios para desenvolver novos conhecimentos e auxiliar pessoas a desenvolvê-los; saber assumir responsabilidades, assumir os riscos pelas consequências se seus atos; e ter visão estratégica, para conhecer e entender o funcionamento da organização para analisar as oportunidades. Desta forma, é possível compreender que para se ter competência não é necessário ser de origem tecnológica, ela pode estar associada ao controle dos negócios, como, conhecimento das condições mercadológicos.

De acordo com Morcerf, Seabra e Vilas Boas (2006), a gestão de competências é utilizada como ferramenta para desenvolver e aprimorar os saberes críticos, necessários para o sucesso da empresa. Segundo o autor, a gestão por competência proporciona diversos tipos de saberes, o saber, como forma de conhecimento, o saber fazer, como forma de habilidade, e o saber ser por meio do convívio e da forma de agir, que o direciona a determinada atitude, esses saberes contribuem para o desenvolvimento de aspectos, como a liderança e o fortalecimento da imagem organizacional. Dessa forma, é possível observar os resultados da utilização do modelo de gestão por competência, onde ele possibilita uma melhor compreensão da organização, propagação de conhecimento, e uma maior ligação entre os setores da empresa.

O presente modelo da gestão por competência deve ser entendido como a junção das políticas empresariais, atividades práticas dos colaboradores, padrões de normatização, atitudes organizacionais, ações e instrumentos utilizados por uma organização para modificar e redirecionar o comportamento dos colaboradores na empresa (DUTRA, 2004). Segundo o autor, o conjunto de políticas e práticas de Gestão de Pessoas deve possuir as seguintes propriedades:

Integração entre si - Essa integração permite ao gestor avaliar os desdobramentos de uma decisão relativa à remuneração de uma 
pessoa no conjunto das remunerações da organização, na massa salarial, no sistema de carreira, no sistema de desenvolvimento, enfim, em todos os demais aspectos da gestão de pessoas dentro da organização. Integração com a estratégia organizacional - É fundamental que o conjunto de políticas e práticas de gestão de pessoas estejam alinhadas com os objetivos da organização, seus valores e missão. (DUTRA, 2004, p. 34)

E finalmente, segundo Dutra (2008), há a necessidade de Integração com as expectativas das pessoas - É fundamental, também, que essas políticas e práticas estejam alinhadas com as expectativas das pessoas para ter a legitimidade necessária para sua efetividade. O presente modelo visou estipular objetivos e metas a serem alcançados, de acordo com a intenção e estratégia da organização, a partir disto, é necessário identificar a lacuna entre as competências que a empresa dispõe. Então, inicia-se o planejamento, a seleção, o desenvolvimento e a avaliação das competências dos colaboradores, buscando reduzir a lacuna, esse processo é realizado através dos subsistemas dos Recursos Humanos, como recrutamento e seleção, treinamento e gestão de desempenho. O objetivo é que a organização reduza a diferença entre o que ele pode fazer, e a demanda exigida pelo público alvo. (STEWART, 1998). Nesse sentido, é possível compreender que a gestão por competência está inclusa num sistema amplo de gestão organizacional.

Tomando como referência as estratégias organizacionais através dos processos de recrutamento e seleção, treinamento, gestão de carreira e formalização de alianças estratégicas, com o intuito de auxiliar a desenvolver as competências exigidas para alcançar seus objetivos. De acordo com Baptista (2006), o conceito de competência envolve aspectos relacionados a capacidade do colaborador de gerar resultados positivos e estratégicos dentro dos objetivos da organização. Esses resultados são analisados através de 2 processos, o "output" e o "Input". O Output é o mapeamento dos resultados esperados pela empresa, e o Input é o conjunto de habilidades, conhecimentos, e atitudes necessários para atingir o resultado. Dessa forma, a organização busca desenvolver essas competências que ajudem a alcançar as estratégias da empresa. Estratégias que por sua vez são replicadas, e adaptadas ás instituições públicas para a otimização dos produtos e serviços oferecidos aos cidadãos. A gestão por competência é uma ferramenta que pode ser usada com diversos focos na gestão de pessoas, a depender do objetivo, no Quadro 1 Baptista (2006) apresenta seus pontos atuação.

Quadro 1. Aplicação da gestão por competência como ferramenta da gestão de pessoas em relação ao seu objetivo

\begin{tabular}{|c|c|}
\hline Aplicação & Objetivo \\
\hline $\begin{array}{l}\text { Recrutamento e } \\
\text { seleção }\end{array}$ & $\begin{array}{l}\text { Utilizar os conhecimentos requeridos (o saber) como requisitos de acesso } \\
\text { na captação de pessoas com nível educacional elevado. }\end{array}$ \\
\hline Avaliação & $\begin{array}{l}\text { Como ferramenta para avaliação de desempenho considerando as } \\
\text { competências requeridas e as efetivamente apresentadas pelos empregados; }\end{array}$ \\
\hline $\begin{array}{l}\text { Desenvolvimento } \\
\text { profissional }\end{array}$ & $\begin{array}{l}\text { Peça-chave das práticas de gestão por competência. Considera não somente } \\
\text { as políticas desenvolvidas pela empresa para educação e treinamento, como } \\
\text { também a questão do auto desenvolvimento. }\end{array}$ \\
\hline Remuneração & $\begin{array}{l}\text { Remuneração variável, participação de resultados e a remuneração fixa, } \\
\text { tomando como base as competências individuais; a ligação da remuneração }\end{array}$ \\
\hline
\end{tabular}

Fonte. Baptista (2006) 
Como descrito no Quadro 1, é possível aplicar a gestão por competência com foco no recrutamento e seleção, onde vai ser analisado o que o candidato sabe, e quais os conhecimentos que ele obtém para a requerida vaga, avaliando o nível educacional da pessoa e como ela direciona os seus conhecimentos para o trabalho. No setor de avaliação, é utilizado para identificar o desempenho dos colaboradores, quais as competências requeridas e quais não estão presentes, com o intuito de informar ao colaborador para que o mesmo possa alcançar determinada competência. Para o desenvolvimento profissional, é de extrema importância, pois proporciona para o colaborador um autodesenvolvimento, por meio da educação e treinamento, seja ele profissional ou pessoal (BAPTISTA, 2006).

Quanto à remuneração variável é possível atuar relacionando as competências através da participação nos lucros, quanto mais metas alcançadas, maior a remuneração, no entanto a remuneração fixa também envolve as competências, pois o nível da remuneração será equivalente ao cargo e as competências que o cargo exige. Existe também a relação entre a remuneração e a avaliação de desempenho, uma boa avaliação pode gerar bônus financeiro ao colaborador. (BAPTISTA, 2006). Segundo Baptista (2006), para realizar a implantação de uma gestão por competência efetiva é necessário que a organização tenha alguns pré-requisitos descritos no Quadro 2.

Quadro 2. Pré-requisitos da organização para implantar uma gestão por competência

\section{Pré-requisitos}

Ser simples

Ser transparente

Ser instrumental

Ser integrado

Ser compatibilizador

Ser abrangente.

\section{Objetivos}

De fácil entendimento e operacionalização

Garantir acesso das informações e oportunidades a todos os empregados

Operacionalizar os conceitos empregados na prática

Atender as diversas necessidades da gestão de pessoas (Recrutamento e Seleção, Carreira, Educação, Treinamento e Desenvolvimento, Remuneração e Avaliação, entre outras)

Trazer benefícios tanto para empresas quanto para os empregados

Adaptar-se às diversas áreas da organização

O modelo destacado na Figura 1 apresenta as etapas para a implantação de uma gestão por competência. É possível observar como funciona o processo de implantação de uma gestão por competências. $O$ processo se inicia com o direcionamento estratégico, é preciso ter bem delimitado a visão, missão, objetivos e estratégias da organização, então o processo começa já nessa etapa, denominada por Dutra et al. (1999) como etapa zero, onde ocorre a análise estratégica.

Nesta análise serão identificadas as competências essenciais que a organização deve ter, levando em consideração essas competências essenciais como plano de fundo para o desenvolvimento das estratégias e competências individuais. Ou seja, é a partir das competências essenciais que se identificam quais as competências que os colaboradores deverão apresentar.

Após analisar as competências essenciais e descobrir quais as competências individuais que os colaboradores devem ter para ocupar os respectivos cargos inicia a etapa 1, de identificação, mapeamento e comunicação, por meio das competências individuais selecionadas no processo seletivo é possível agregar valor corporativo, delimitar os eixos de trabalho e as habilidades agregadas com os colaboradores. Em 
seguida inicia-se a etapa 2, de avaliação das competências dos colaboradores, pois através da contínua avaliação de desempenho e das competências é possível identificar quais competências o funcionário já tem e quais ele precisa desenvolver.

Proporcionando para o colaborador uma continua evolução e desenvolvimento profissional e pessoal. Por fim, na etapa 3, é realizado esse filtro das competências e realizado processos de treinamento e desenvolvimento profissional para auxiliar $\mathrm{o}$ funcionário a se desenvolver (DUTRA; HIPÓLITO; SILVA, 1999, p.20).

Figura 1. Implementação do Sistema de Gestão por Competências

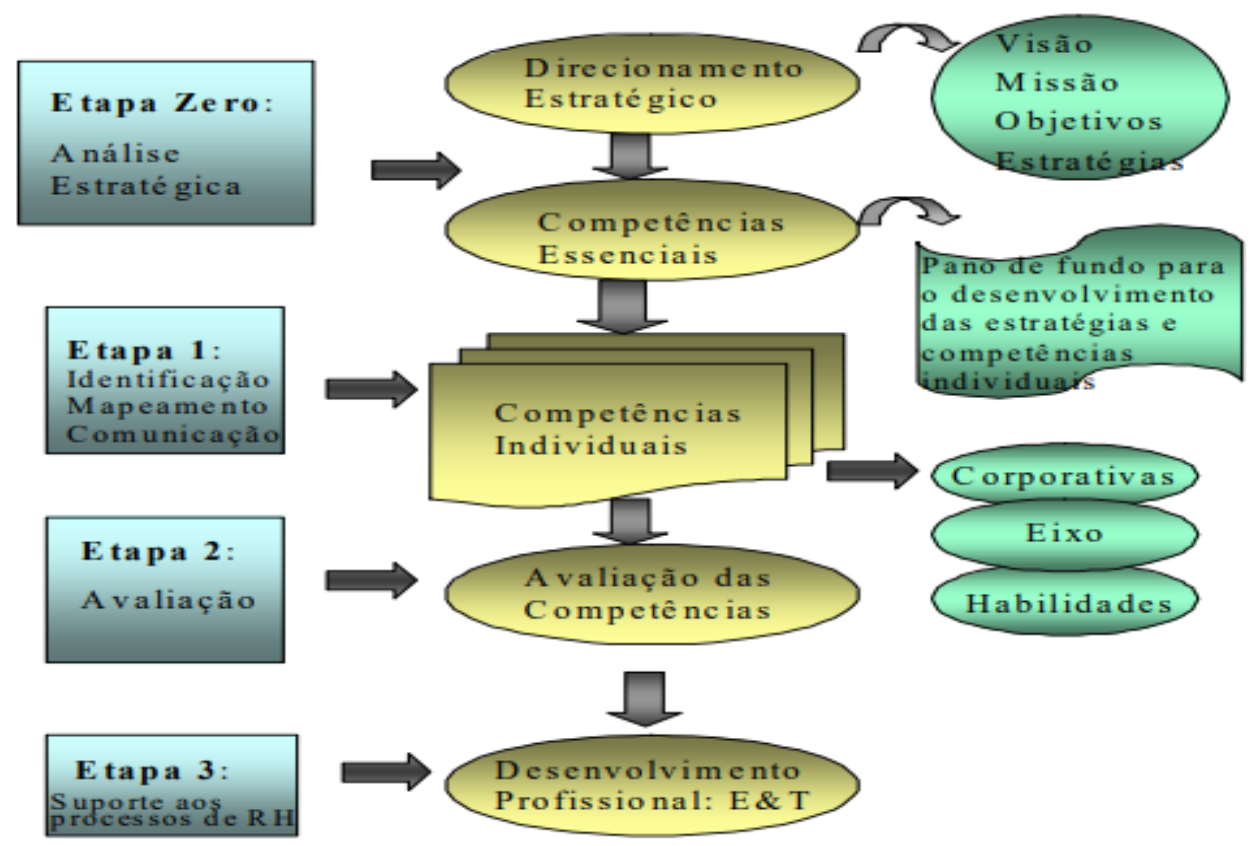

Fonte. Adaptação de Dutra (1999 apud BAPTISTA, 2006, p. 123)

\subsection{DIFICULDADES DA GESTÃO POR COMPETÊNCIA}

Segundo Retour (2001), a implantação da Gestão de Competências apresenta duas dificuldades mais nítidas, a falta de unicidade sobre os conceitos e as práticas do processo de gerir através de competências e complexidade, referente a execução do sistema de implantação, caracterizado por problemas, no que se refere a avaliação das competências e na distinção do que é individual, para o coletivo.

Em relação ao método de operação da gestão por competências, Rocha e Salles (2005) frisam que os modelos se baseiam no conceito de excelência, exigindo um desenvolvimento de um processo estruturado que abarque todas as etapas da gestão de recursos humanos com métodos específicos para este modelo de gestão.

Outros fatores relevantes, citados por Oliveira, Penna, Lopes e Barbosa (2009), estão relacionados à falta de solidez no que concerne a estruturação das competências organizacionais elencadas pelas empresas. Assim como, não priorizar o modelo da gestão por competência como modelo fundamental para as diretrizes. A ausência de um gestor que proporcione a mudança para a execução do modelo por competência. Como também ao baixo nível de modernidade observado nas empresas brasileiras, o que 
dificulta a implantação do modelo, assim como a falta de proximidade na estrutura hierárquica da organização.

\subsection{FORMAS DE SOLUCIONAR AS DIFICULDADES DA GESTÃO POR COMPETÊNCIA}

De acordo com Guimarães et al. (1999), a melhor forma de solucionar as dificuldades está em relacionar a Gestão por Competências com a Gestão de Desempenho. Tendo em vista que derivam do mesmo constructo, com o sentido de complementariedade melhor seria nomeá-la de Gestão de Desempenho Baseada nas Competências, pois ambas proporcionam uma interdependência entre competência e desempenho. Tendo em vista as falhas de ambos os modelos, faz-se necessário uni-los em metodologias, pois para que ambos funcionem, é preciso incluir em um único processo as atividades de planejamento, acompanhamento, avaliação de desempenho, que se baseie nas competências essenciais da organização. Tanto no nível corporativo, quanto no nível individual.

$\mathrm{Na}$ Figura 2, pode-se observar o funcionamento do Modelo de Gestão de Desempenho Baseado em Competências proposto por Guimarães et al. (1999). O que explicaria o motivo de uma possível releitura nos conceitos já estipulados, possibilitando a um uso mais adequado em ambientes com mais complexidade de gestão, onde a demanda de serviços seja maior e mais segmentada, resultando em um escopo maior de análise dos resultados obtidos depois da utilização do novo modelo adaptado.

Figura 2. Modelo de gestão de desempenho baseado nas competências

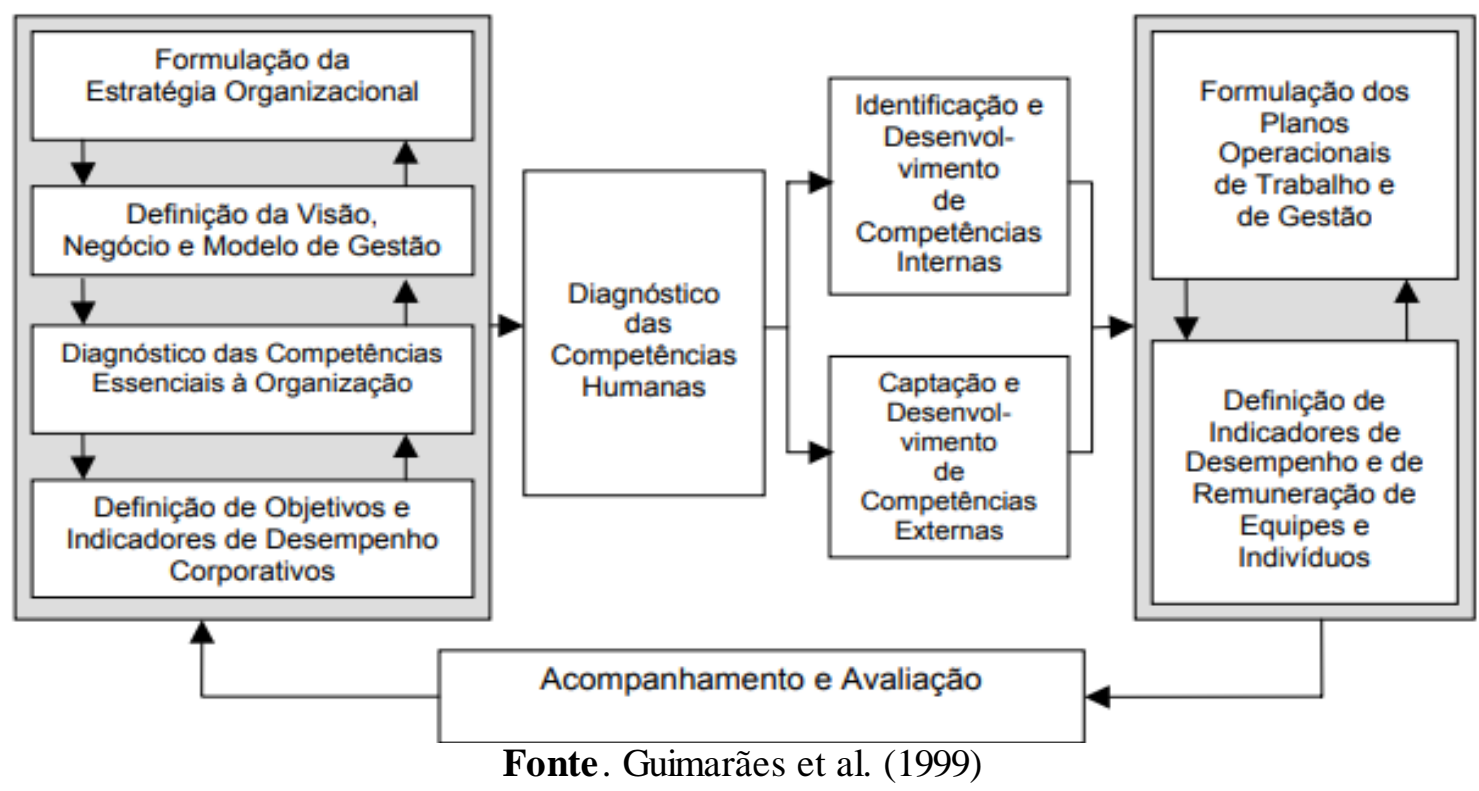

Como é possível observar na Figura 2, o processo de implantação de uma gestão de desempenho baseado nas competências inicia-se com a formulação das estratégias organizacionais, a definição da visão, negócio e modelo de gestão que se decide empregar, faz-se o diagnóstico das competências essenciais à organização para que ela seja considerada única, e a definição dos objetivos e indicadores de desempenhos coorporativos. Em seguida é realizado um diagnóstico das competências 
humanas que a empresa necessita para determinados cargos. No terceiro ponto do diagrama é efetuado a identificação e desenvolvimento de competências internas, com as pessoas que já sejam colaboradores da empresa, assim como a captação e desenvolvimento de competências externas, através da contratação de novos colaboradores que obtenham as competências necessárias para ocupar os cargos naquele momento.

Após esta fase é realizado a formulação dos planos de operação de trabalho e gestão com base nas competências já existentes e nas adquiridas com a captação externa. Junto a formulação dos planos está a definição dos indicadores de desempenho que serão avaliados, de remuneração, de equipes e indivíduos. Após o estabelecimento dessas definições é realizado o acompanhamento do funcionamento do modelo e a avaliação dos resultados, para que por meio destes possa se manter o processo ou formular novas estratégias, e começar todo um novo processo de implantação.

Por meio disto, é possível perceber que o principal desafio das empresas se associa a utilização dos instrumentos de avaliação das práticas de aprendizagem, do desenvolvimento de equipes e outros relacionados a competência e desempenho, que proporcionem oportunidades de desenvolvimento pessoal e profissional. Que estimulem os colaboradores a compartilhar o que desenvolveu com outras pessoas. Caso contrário, seria uma tentativa de modernização, sem reais inovações no âmbito de gestão.

Segundo Celestino (2005), o desenvolvimento e compartilhamento dessas competências pode ser efetuado através do processo do Coaching. Para Kolb (1997), o processo do coaching se baseia na teoria de reflexão e ação, unida ao conceito de autodesenvolvimento e aprendizagem organizacional. É possível compreender que, no momento que o coaching é aplicado ao desenvolvimento ou aprimoramento de competências, não se limitam apenas a essas áreas, ocorre um desenvolvimento total, em nível de desempenho e liderança, considerando "focos irradiadores de excelência, que tendem a se expandir pelo sistema organizacional como um todo" (KRAUSZ, 2007, p. 28).

\subsection{RELAÇÃO ENTRE O COACHING E A GESTÃO POR COMPETÊNCIAS}

De acordo com Grant e Cavanagh (2004), o processo do coaching aplicado às organizações, pode ser dividido em três fases. Como apresentado no Quadro 3.

Quadro 3. Fases do desenvolvimento do coaching

\begin{tabular}{|l|l|l|}
\hline Fase & Período & Característica \\
\hline Atividade interna & 1930 a 1960 & $\begin{array}{l}\text { Coaching interno; atividade exercida pelo supervisor hierárquico; forma } \\
\text { de treinamento. }\end{array}$ \\
\hline Rigor acadêmico & 1960 a 1990 & $\begin{array}{l}\text { Período em que documentos submetidos à apreciação de pares começam } \\
\text { a ser publicados; pesquisas e discussões atendem maior rigor acadêmico. }\end{array}$ \\
\hline $\begin{array}{l}\text { Ciência e pesquisas } \\
\text { científicas }\end{array}$ & $\begin{array}{l}\text { A partir de } \\
1990\end{array}$ & $\begin{array}{l}\text { Crescimento de teses, dissertações e artigos acadêmicos sobre atividade } \\
\text { de coach externo nas organizações. }\end{array}$ \\
\hline
\end{tabular}

Fonte. Os autores (2020) 
Segundo Lopez (2016), a avaliação dos resultados do processo de coaching é primordial, pois traz informações relevantes para justificar a utilização desse processo como ferramenta de desenvolvimento pessoal, principalmente quando se refere ao valor dos investimentos necessários para se aplicar o processo. Esses resultados podem servir também como base para avanços científicos no ramo do coaching.

Além de todos os benefícios pessoais e profissionais que surgem no decorrer do processo, o coaching auxilia no processo de humanização das organizações, pois propicia para as equipes um clima organizacional de acolhimento e apoio, que proporciona desenvolvimento de forma mais eficaz, gerando assim aprendizagem e ampliação das competências de cada colaborador. Proporciona também maior interação entre líderes e liderados e contribuem para formar equipes de auto rendimento, as quais priorizam excelência profissional, em seus variados aspectos da organização. (DI STÉFANO, 2005). Desta maneira, o coaching desenvolve um perfil diferencial aos profissionais que aderem ao processo. Como diria Bender (2009, p. 99), “[...] nenhuma marca bem-sucedida atingiu o sucesso por ser normal. $\mathrm{O}$ sucesso está ligado à criação de algo novo, diferente".

A partir deste pensamento, a principal consequência do processo do coaching, refere-se a proporcionar mudanças significativas comportamentais e de atitude aos coachees, tornando, assim, os profissionais, sujeitos singulares, e mais aptos a atuarem no mercado. Por meio de sua mudança, passam a se enxergar de forma diferente, e conseguem fazer com que as outras pessoas enxerguem essa mudança pessoal, e aumentem seu valor de mercado. Desta forma, o coaching é um processo que permite visualizar que, buscar pelo sucesso é melhor que procurar a perfeição. Não significando isto que seja a única ferramenta gerencial para a melhoria da instituição ou organização, mas é um importante processo de melhoria e aumento de produtividade mais integrada.

\section{PROCEDIMENTOS METODOLÓGICOS}

O presente trabalho abordou como tema a gestão por competências, o significado de competência para os principais autores que se referem ao tema, como funciona o processo da gestão por competências e quais as dificuldades para a implementação do modelo de gestão por competências, assim como, foi abordado as formas de solucionar essas dificuldades e o coaching como a principal forma de sanar essas dificuldades, pois a partir do processo do coaching é possível desenvolver as competências necessárias para a aplicação do modelo.

O presente trabalho é uma pesquisa qualitativa, de campo. Pois foi realizado um questionário aberto contendo 10 questões que abordam a presença do coaching na gestão por competência, e como ele pode agregar valor para o processo de gestão. O questionário foi aplicado com os funcionários da Secretaria de Estado do Planejamento, Gestão e Patrimônio (SEPLAG/AL), com o objetivo de coletar dados sobre a aplicabilidade do coaching na gestão por competência.

O método hipotético-dedutivo foi utilizado nesta pesquisa, pois foram utilizadas pesquisas em contextos amplos para comprovar as hipóteses propostas no contexto do presente tema. $\mathrm{O}$ universo abordado foi o da gestão por competência e as formas de desenvolver as competências necessárias para o desenvolvimento da equipe. O material coletado dos livros, periódicos, artigos científicos entre outras fontes foram utilizados no arcabouço teórico-metodológico da pesquisa. 
Após o aprofundamento na bibliografia, foi possível redigir um questionário para obter informações diretas de pessoas que vivenciaram a aplicação deste modelo. $\mathrm{O}$ questionário elaborado consta de 10 perguntas relacionadas ao modelo da gestão por competências, para que por fim, se fizesse possível compreender quais as dificuldades da gestão por competências e de quais formas foi possível solucionar essas dificuldades. E onde o Coaching pode influenciar nesse processo.

\section{ANÁLISE E DISCUSSÃO DO RESULTADOS}

Por meio do presente estudo foi possível compreender o funcionamento do modelo de Gestão por Competência, o que é necessário para realizar uma implantação bem-sucedida do modelo. Foram encontrados 24 autores que abordam o tema da gestão por competência, onde por meio destes, foram retirados os diversos conceitos de Competência, os tipos de competência e a forma como cada autor compreende o tema. Foi com base nesses autores também, que foram observados os pré-requisitos que as empresas necessitam ter para realizar o processo de implantação. Assim como, por meio dos mesmos, foi possível compreender as vantagens e desvantagens do novo modelo, e as principais dificuldades para sua execução.

Associado aos argumentos dos autores anteriormente citados foi utilizado o questionário aplicado na SEPLAG, que confirmam parcialmente e num recorte temporal, os argumentos a partir das respostas dos funcionários que vivenciaram o processo.

Tabela 1. O coach ajuda a desenvolver e aprimorar as competências profissionais do seu setor de trabalho?

\begin{tabular}{ccc} 
Resposta & Porcentagem & Quantidade de pessoas \\
Sim & $90,90 \%$ & 10 \\
Não & $0 \%$ & 0 \\
Sem resposta & $9,09 \%$ & 1 \\
Total & & 11 \\
\hline
\end{tabular}

Fonte. a pesquisa

De acordo com as informações coletadas no questionário, foi possível constatar na Tabela 1, que 90,90\% das pessoas acreditam que o coach é um profissional que auxiliaria no processo de desenvolvimento de habilidades dentro dos seus setores, agregados a essas respostas os funcionários responderam que também pode auxiliar no desenvolvimento de motivação, organização, habilidades no setor interno e externo da empresa, como em muitas outras áreas.

Tabela 2. O coach em gestão de pessoas tem papel importante na instituição?

\begin{tabular}{ccc} 
Resposta & Porcentagem & Quantidade de pessoas \\
Sim & $100 \%$ & 11 \\
Não & $0 \%$ & 0 \\
Sem resposta & $0 \%$ & 0 \\
Total & & 11 \\
\hline
\end{tabular}

Fonte. a pesquisa 
Assim como afirmam os autores citados, as respostas dos entrevistados concordaram que o papel do coaching é de extrema importância para o desenvolvimento e aplicação do novo modelo de gestão por competências. Pode-se ver na Tabela 2 que $100 \%$ das pessoas afirmaram, que o coaching contribui positivamente para o processo, pois ele possibilita para os funcionários, $\mathrm{o}$ desenvolvimento de habilidades $\mathrm{e}$ competências que farão com que o funcionário evolua, tanto profissionalmente, quanto pessoalmente.

Tabela 3. O trabalho do coach na instituição na qual você trabalha trará benefícios para instituição?

\begin{tabular}{ccc} 
Resposta & Porcentagem & Quantidade de pessoas \\
Sim & $100 \%$ & 11 \\
Não & $0 \%$ & 0 \\
Sem resposta & $0 \%$ & 0 \\
Total & & 11 \\
\hline
\end{tabular}

Fonte. a pesquisa

Como se vê na Tabela 3, unanimemente, os funcionários que responderam o questionário, concordam que assim como o trabalho do coach na empresa para qual trabalham é de extrema importância, afirmam também que o trabalho do coach pode trazer vários benefícios, como uma melhora na organização dos funcionários, e consequentemente da empresa, melhora na motivação de todos os trabalhadores, melhor entrosamento entre a equipe, a comunicação, tanto entre os membros dos setores, quanto entre os setores, e uma boa adaptação ao trabalho.

Tabela 4. Já precisou lidar com diferentes decisões a serem tomadas no mesmo dia?

\begin{tabular}{ccc} 
Resposta & Porcentagem & Quantidade de pessoas \\
Sim & $90,90 \%$ & 10 \\
Não & $9,09 \%$ & 1 \\
Sem resposta & $0 \%$ & 0 \\
Total & & 11 \\
\hline
\end{tabular}

Fonte. a pesquisa

Assim como os pontos citados nas respostas dos funcionários à pergunta anterior, pode-se observar na Tabela 4 outro ponto em que o coach pode auxiliar os funcionários. A tomada de decisões é habilidade que muitos cargos exigem, principalmente, para os cargos de liderança. E das pessoas que responderam ao questionário, 90,90\% já tomaram, decisões e tomam durante seus dias de trabalho. E é perceptível que esse processo se torna visivelmente mais fácil com a atuação de um coach na equipe.

Tabela 5. Já implementou mudanças no seu ambiente de trabalho?

\begin{tabular}{ccc} 
Resposta & Porcentagem & Quantidade de pessoas \\
Sim & $54,54 \%$ & 6 \\
Não & $27,27 \%$ & 3 \\
Sem resposta & $18,18 \%$ & 2 \\
Total & & 11 \\
\hline
\end{tabular}

Fonte. a pesquisa 
Apesar de duas pessoas não responderem a esta pergunta do questionário, como vemos na Tabela 5, 54,54\% dos funcionários já realizaram mudanças no seu ambiente de trabalho, assim como $27,27 \%$ não realizam mudanças, é possível perceber por meio deste quadro que efetuar mudanças nos setores é um processo difícil, que exige muita análise do funcionamento do setor, e das pessoas que trabalham nele. Por isso se faz necessário a utilização de um coach para este processo, pois ele auxilia no processo de análise dos funcionários e da empresa, e orienta o gestor na mudança que o mesmo deseja realizar.

Tabela 6. Mediou conflitos com clientes internos ou externos?

\begin{tabular}{ccc} 
Resposta & Porcentagem & Quantidade de pessoas \\
Sim & $45,45 \%$ & 5 \\
Não & $45,45 \%$ & 5 \\
Sem resposta & $9,09 \%$ & 1 \\
Total & & 11 \\
\hline
\end{tabular}

Fonte. a pesquisa

Assim como, a tomada de decisões, e as mudanças dos ambientes, a mediação de conflitos é um papel importante para os gestores e líderes, de qualquer setor ou nível hierárquico da empresa. E como se pode ver na Tabela 6 , muitas pessoas ainda têm dificuldades em mediar conflitos dos funcionários, no entanto esta é uma habilidade que pode ser aprendida e efetuada com melhores resultados quando realizado em concomitância com o processo do coaching.

Tabela 7. Reconheceu uma situação em que o erro de decisão foi totalmente seu?

\begin{tabular}{ccc}
\hline Resposta & Porcentagem & Quantidade de pessoas \\
Sim & $63,63 \%$ & 7 \\
Não & $36,36 \%$ & 4 \\
Sem resposta & $0 \%$ & 0 \\
Total & & 11 \\
\hline
\end{tabular}

Fonte. a pesquisa

Dentre todos os pontos anteriormente citados, na Tabela 7 um tópico que prejudica gravemente o trabalho de um gestor, é o fato de muitos não terem um bom reconhecimento de suas próprias falhas, apesar de 63,63\% das pessoas responderem que reconhecem suas falhas, ainda é um ponto que dificilmente é reconhecido sua existência, pois muitos acreditam que reconhecendo seus próprios erros estão se inferiorizando, mas no processo de coaching pode vir melhorar seu autoconhecimento e aceitar melhor suas próprias falhas.

Tabela 8. Periodicamente você recebe feedback do seu gestor imediato, sobre suas ações?

\begin{tabular}{ccc} 
Resposta & Porcentagem & Quantidade de pessoas \\
Sim & $63,63 \%$ & 7 \\
Não & $36,36 \%$ & 4 \\
Sem resposta & $0 \%$ & 0 \\
Total & & 11 \\
\hline
\end{tabular}

Fonte. a pesquisa 
$\mathrm{Na}$ Tabela 8 é possível observar que alguns não recebem feedback de seus gestores, no entanto esse trabalho é de extrema importância, tanto paga o funcionário, quanto para o processo do coaching, pois por meio do feedback é possível avaliar o como está sendo e de que forma estão ocorrendo as evoluções realizadas no decorrer do processo.

$\mathrm{Na}$ pergunta 9 do questionário foi investigado o que as pessoas pensam a respeito do novo modelo de gestão por competência, e em todas as respostas foi possível ver uma concordância em dizer o quanto o modelo de gestão por competências é benéfico tanto para a empresa, quanto para os funcionários, que também confirma com os dados apresentados na Tabela 9, onde $100 \%$ das pessoas responderam que veem a gestão por competência como uma tendência a ser implementada nas instituições.

Tabela 9. Atualmente você vê a gestão por competências como uma tendência a ser implementada nas instituições?

\begin{tabular}{ccc} 
Resposta & Porcentagem & Quantidade de pessoas \\
Sim & $100 \%$ & 11 \\
Não & $0 \%$ & 0 \\
Sem resposta & $0 \%$ & 0 \\
Total & & 11 \\
\hline
\end{tabular}

Fonte. a pesquisa

Com base nas dificuldades apresentadas pelos autores para a implantação do novo modelo de gestão, foi perceptível que as dificuldades para a implantação da Gestão por Competências giram em torno de alguns pontos, como, a falta de unicidade no conceito de Competência, o que torna difícil para os gestores que tentam realizar a mudança, pois muitos não identificam da forma correta o que seriam as competências necessárias para efetuar o processo.

Outra dificuldade está no fato de as empresas consideradas "conservadoras" não priorizarem a valorização do capital intelectual e sim o capital tecnológico. Fazendo com que muitos dos colaboradores não trabalhem com foco nos valores e estratégias da empresa, e sim com foco no salário. Fazendo com que ao primeiro sinal de uma proposta melhor, eles abandonam a organização. Assim como a hierarquização das organizações e a relutância dos gestores em interagirem e se integrarem com os funcionários, podendo limitar a aplicação do modelo.

Nesta pesquisa, realizada na secretaria de estado, observou-se uma dificuldade na aderência ao Modelo de Gestão por Competência, pois houve a carência de um estudo prévio para identificar as competências necessárias, pois foi utilizada pela SEPLAG uma metodologia já pronta para a execução do mesmo. O que acaba colidindo com as necessidades das competências essenciais da instituição, mas não se constituindo um aspecto de generalização, necessitando pesquisas mais abrangentes.

No entanto, o ponto chave desta pesquisa é a resolução de mais uma dificuldade encontrada, a de localizar e desenvolver as competências individuais que cada colaborador tem a agregar as competências organizacionais das empresas. Por meio da análise de mais 10 artigos sobre o Coaching e com a pesquisa efetuada, foi possível constatar que o coaching, apesar de ser um recurso considerado caro para a aplicação, é uma ferramenta importante para auxiliar na gestão por competência, pois possibilita, com técnicas de avaliação de desempenho, os colaboradores possam descobrir os quesitos problemáticos, e com o acompanhamento do coaching, encontrar 
formas de desenvolver as competências que faltam para melhorar no seu desempenho. E por sua vez, auxilia no desenvolvimento humano, aumenta o capital intelectual das organizações e melhora o desempenho da organização como um todo.

\section{CONSIDERAÇÕES FINAIS}

A partir do que foi abordado na presente pesquisa, foi possível concluir que o Modelo de Gestão por Competência é entendido como um avanço no ramo da Gestão de pessoas, pois permite às organizações uma maior competitividade, e aos colaboradores permite uma visão mais humanizada. Pois seu foco visa, tanto o desenvolvimento pessoal e profissional, de seus colaboradores, quanto através do desenvolvimento dessas competências, o modelo permite ampliar as competências organizacionais.

No entanto, apesar dos benefícios apresentados neste estudo, é possível visualizar que muitas empresas não aderem ao novo modelo, por diversos motivos, como conservadorismo dos antigos gestores, falta de clareza a respeito do conceito, falta de unificação entre os setores da empresa, onde a presente hierarquização não permite a compreensão e observação das competências individuais de cada colaborador.

Apesar de todos os pontos citados anteriormente, o coaching surge como uma ferramenta que possibilita uma visão analítica dos colaboradores, proporcionando uma evolução pessoal e profissional, dentro e fora da organização. Por meio do trabalho do coaching unido ao gestor, é possível realizar uma implantação da Gestão por Competência somando as competências de liderança e compreensão da empresa que o gestor possui, com as técnicas de avaliação e desempenho, e as técnicas de desenvolvimento pessoal do coaching, possibilitando uma avaliação estratégica da empresa e assim, compreender como deve ser feito a estrutura de competências que os funcionários devem ter para suprir as exigências das organizações que os mesmos estão inseridos.

\section{REFERÊNCIAS}

BAPTISTA, J. L. P. Uma proposta para empresa de capital intelectual intensivo. Pontifícia Universidade Católica de São Paulo. São Paulo, 2006.

BARRETO, A. M. O fator humano e o desenvolvimento de competências nas unidades de informação. Perspectivas em ciência da informação, Belo Horizonte, v. 10, n. 2, 2005.

BENDER, A. Personal branding: construindo sua marca pessoal. São Paulo: Integrare, 2009.

CELESTINO, S. O executivo e o coaching em marketing pessoal. Revista Eletrônica Consultores de Consultores. 2005.

DI STÉFANO, R. O Líder-Coach: líderes criando líderes. Rio de Janeiro: Qualitymark, 2005. 
DUTRA, J. S. Competências: Conceitos e instrumentos para a gestão de pessoas na empresa moderna. São Paulo: Atlas, 2004.

DUTRA, J. S.; FISCHER, A. L.; RUA, R. DE L.; NAKATA, L. E. Absorção do Conceito de Competência em Gestão de Pessoas: a Percepção dos Profissionais e as Orientações Adotadas pelas Empresas. In: DUTRA, J. S.; FLEURY, M. T. L.; RUAS, R. (Orgs.). Competências: conceitos, métodos e experiências. São Paulo: Atlas, 2008.

DUTRA, J.; HIPÓLITO, C.; SILVA, C. Gestão de pessoas por competência: o caso de uma empresa no setor de telecomunicações. In: Encontro Nacional da Associação Nacional de Pós-graduação e Pesquisa em Administração, 22, 1999, Foz de Iguaçu PR. Anais [...]. Foz do Iguaçu: Enanpad, Anpad, 1999.

FLEURY, M. T.; FLEURY, A. Estratégias empresariais e formação de competências. São Paulo: Atlas, 2004.

GRANT, A. M; CAVANAGH, M. Toward a profession of coaching: sixty-five years of progress and challengs for the future. International Journal of Evidence Based Coaching and Mentoring, 2, v n. 1, p. 8-21, 2004.

GUIMARÃES, T.A. GUIMARÃES，T.A.; BORGES-ANDRADE，J.E.; MACHADO, M.; VARGAS, M.R.M. Diagnóstico de Competências Essenciais em Ambiente de Inovação Tecnológica. No prelo, 1999.

KOLB, D. A gestão e o processo de aprendizagem. In: STARKEY, K. (Org.). Como as organizações aprendem. São Paulo: Futura, 1997.

KRAUSZ, R. R. Coaching executivo: a conquista da liderança. São Paulo: Nobel, 2007.

LOPEZ, V. A. Coaching: modismo ou uma ferramenta de gestão de pessoas que veio para ficar? Pontifícia Universidade Católica, Rio Grande do Sul, 2016.

MORCERF, S. O.; SEABRA, T. C.; VILAS BOAS, J. A. Gestão de Competências Um estudo de Caso. Anais do Simpósio de Excelência em Gestão e Tecnologia, v. 03, p. 01-40, 2006.

OLIVEIRA, J.A.C.K.; PENNA, K.R.S.; LOPES, D.P.T.; BARBOSA; A.C.Q. Dificuldades na Gestão de Competências: uma análise Longitudinal em Grandes Organizações Brasileiras dos Setores de Telecomunicações e Siderurgia. II encontro de gestão de pessoas e relações de trabalho, Curitiba, 2009.

PRAHALAD, C. K; HAMEL, G. The core compentence of the corporation. Harvard Business Review, v. 68, n. three. May/june 1990.

RETOUR, D. La gestion des compétence entre concepts ET applications. Choniques, jan/mar, 2001. 
ROCHA, E. P.; SALlES, J. A. A. Competências e a Gestão de Pessoas. RACRE Revista de Administração CREUPI. São Paulo, v.05, n.09, jan/dez.2005.

STEWART, T. A. Capital intelectual: a nova vantagem competitiva das empresas. Rio de Janeiro: Campus, 1998. 